\title{
THE
}

3-11-2015

\section{Getting the Most out of Third Party Trust Seals: An Empirical Analysis}

Koray Özpolat

University of Rhode Island, koray@uri.edu

Wolfgang Jank

Follow this and additional works at: https://digitalcommons.uri.edu/cba_facpubs

The University of Rhode Island Faculty have made this article openly available.

Please let us know how Open Access to this research benefits you.

This is a pre-publication author manuscript of the final, published article.

Terms of Use

This article is made available under the terms and conditions applicable towards Open Access

Policy Articles, as set forth in our Terms of Use.

\section{Citation/Publisher Attribution}

Koray Özpolat, Wolfgang Jank, Getting the Most out of Third Party Trust Seals: An Empirical Analysis, Decision Support Systems, Available online 11 March 2015, ISSN 0167-9236, http://dx.doi.org/10.1016/ j.dss.2015.02.016. 


\title{
Getting the Most out of Third Party Trust Seals: An Empirical Analysis
}

\begin{abstract}
Electronic markets have successfully adopted third party trust seals as a self-regulatory mechanism to enhance consumer trust. While there exist many papers supporting the effectiveness of trust signals, interaction between trusts seals and contextual factors in e-commerce (e.g., value of shopping carts, number of trust seals displayed, shopper experience and retailer's sales volume) is an underexplored area. In this study, we exploit a dataset of over a quarter million of online transactions across 493 online retailers collected from randomized field experiments. A large trust seal provider conducted the experiments and subsequently shared the dataset with us. Our main contribution is the demonstration of four variables moderating the effectiveness of trust seals on the likelihood of purchase completion. More specifically, our work shows that trust seals are more effective for small online retailers and new shoppers, thus serving as partial substitutes for both shopper experience and seller's sales volume. Interestingly, we find that presence of too many (i.e., more than two) seals can lower the likelihood of purchase completion. Our findings also show that trust seals are more effective for higher value shopping carts but only in the latter stages of the shopping cycle. Finally, we discuss the implications of our findings for online retailers, third party certifiers, as well as for policy makers.
\end{abstract}




\section{Introduction}

Share of e-commerce in total U.S. retail sales has steadily increased to $6.4 \%$ as of the first quarter of 2014 [1]. However, many experts believe that the potential is much higher and attribute the rather slow development of e-commerce to consumers' lack of trust in purchasing on the internet [2]; and this trend not only exists in e-commerce originating in North America but also in India [3] and the Middle East [4]. Quantifying the degree of distrust, TRUSTe 2014 U.S. Consumer Confidence Index [5] shows that 45\% of American consumers do not trust online retailers with their personal information (up from $41 \%$ in 2012). Stressing the importance of initial customer trust for online retailers, Wang, Beatty and Foxx [6, pp.54] bluntly put it as, "failing to overcome the initial trust barriers, all other efforts of online retailers will be in vain".

In order to address this trust gap, online retailers often place trust-inducing features to their websites which "function as a skillful salesperson for the company and moderates the disadvantages of an impersonal website" [7, pp.115]. On top of a retail website's graphic, structure and social cue designs, many small online retailers associate their websites with more reputable and well-known businesses to transfer trust [8]. For example, selling products of well-known brands or displaying reputable companies as technology providers (e.g., Microsoft, VeriSign) can help small online retailers persuade nervous customers. Relying on this notion of trust transfer, third party trust seals (to be called "trust seals" in the rest of the paper) may help new shoppers develop initial trust in the online retailer without prior transaction history at the retailer's website [9]. In this mechanism, an independent third party verifies the reliability and trustworthiness claims of the online retailer and allows its trust seal logo to be displayed at the retailer's website as a proof of endorsement. Clicking this trust seal logo takes the customer to the certification information at the seal provider's website.

The value and effectiveness of trust seals in e-commerce has long been investigated by researchers [10, $11,12,13,14,15,16,17]$ which made important contributions to our understanding of trust seals. Absent in these papers are the contextual factors that facilitate the functioning of trust seals. For example: Should 
an online retailer display the trust seal(s) uniformly to all shoppers? Do all online retailers benefit equally from these seals? Do more trust seals displayed result in higher confidence of the consumer?

Filling these gaps, this paper complements the trust seals literature in two ways. Our first contribution is to the management of trust seals at online retail websites. Extending the current e-commerce literature, we identify various contextual factors that influence the value of the trust seal (i.e., moderate the effect of trust seals on transactions); such as shopping cart value, shopper experience, presence of other trust seals and retailer sales volume. This information is useful for both researchers and practitioners because the effect of the trust seal is not uniform but depends on a set of contextual factors. Our second contribution is methodological. In this study, we exploit a unique experimental dataset comprising over a quarter of a million actual shopping carts and a broad range of product categories from 493 online retail websites. Academic literature in trusts seals has mostly relied on data originating from a single online retailer and product category [10], use observational eBay data [13], or use simulated retail web sites in lab settings [16]. By utilizing a large dataset (multiple retailers and product categories) of actual shopping carts collected through a randomized field experiment, we add to the diversity of methodologies employed by the trust seals literature and make a methodological contribution as well.

A key aspect of our dataset that enhances its empirical value is the presence of randomized field experiment (also called random seal tests). To measure the impact of its trust seal on key site metrics, the seal provider conducts "A/B split tests" at the participating online retail websites upon retailer certification by the seal provider. In this test, the participating retailers allow the seal provider to display the seal with $50 \%$ of the visitors to their web sites - so called A's - while not displaying the seal with the other $50 \%$ - called B's. The assignment of website visitors to A or B is random which ensures that there are no systematic differences between the two sets of shoppers other than the presence of the trust seal. Thus, the "A/B split test" allows us to establish causality and identify the seal's interaction with other variables. In fact, the A/B split test methodology has recently found widespread use outside academia as well, especially after its successful use in President Obama's 2008 and 2012 election campaigns. Deputy Director of the 2012 campaign Kyle Rush [18] reports, "Optimization was the name of the game for the 
Obama Digital team. We optimized just about everything from web pages to emails. Overall we executed about $500 \mathrm{~A} / \mathrm{B}$ tests on our web pages in a 20 month period which increased donation conversions by $49 \%$ and sign up conversions by $161 \% . "$

It is important to note that consumers' buying behavior online is influenced by multiple factors (such as consumer, product and website characteristics) - while the presence of trust seals is only one factor amongst many. Amongst these confounding factors, the randomized seal test methodology isolates the trust seal's impact on purchase completion [10]. However, our unique contribution is identification of moderating factors that influence the seal's effectiveness. We find that the trust seal works better for, (i) low-volume online retailers, (ii) less-experienced shoppers, and (iii) high value shopping carts when the shopper is at a later stage of the shopping cycle. Interestingly, while increasing the number of trust seals at a retailer's site increases the shopper's likelihood of purchase completion, this relationship persists only until a certain optimal number of trust seals and it reverses thereafter.

The rest of the paper is structured as follows. In sections 2 and 3, we first provide an overview of the related literature followed by the development of research hypotheses. Then, we describe the dataset and explain the statistical methodology used to test our hypotheses in section 4. Results are introduced in section 5 . We conclude in section 6 by discussing the contributions of the findings to the literature and impact of our work on seal providers, online retailers and academic literature. Finally, we conclude the paper by discussing limitations and future research opportunities in section 7 .

\section{Theoretical Background}

\subsection{Trust}

Long time ago, Confucius asserted that trust is a fundamental requirement for all social relationships [19]. Trust plays a key role in personal relationships in many different settings including families, schools, groups and organizations. Hirsch [20] assesses the role of trust in economic exchanges and suggests that trust is a "public good" required for a functioning economic system. Viewing commerce as a form of social exchange, it is safe to say that trust matters in online shopping as well. 
Among the many definitions in the literature, Mayer et al. [21, pp.712] define trust as "willingness of a party (trustor) to be vulnerable to the actions of another party (trustee) based on the expectation that the other party will perform a particular action important to the trustor, irrespective of the ability to monitor or control that other party." As trust is operational only when the trustor is vulnerable to the actions of the trustee, many inherent risks (e.g., delivery of faulty products, fraud, compromising private information) make trust an important concept in the context of e-commerce.

In this study, we draw upon the Mayer et al. [21] integrative model of trust (see Figure 1) because it clearly distinguishes between the trustworthiness (of the retailer), trust (in the retailer), and risk-taking (by the consumer), all of which are critical in an online retail context. Exploring the model, on the left side of Figure 1, we see that trustworthiness of the trustee (as perceived by the trustor) is an antecedent of trust and this relationship is moderated by the trustor's individual propensity to trust. Trustor's level of trust in the trustee is then compared with trustor's level of perceived contextual risk. If level of trust is higher than the level of risk, trustor takes risk in the relationship. Finally, the outcomes of this relationship are fed back by a loop. While positive outcomes of the risk taking in the relationship enhance the perceived trustworthiness of the trustee, negative outcomes could erode it over time. Early in a relationship, there is not much accumulated feedback yet and trustworthiness perceptions could be built based on trustee's reputation and third party information. This integrative model of trust will be applied to e-commerce in the motivation of hypothesis in section 3 .

Figure 1: Mayer et al. (1995) integrative model of trust

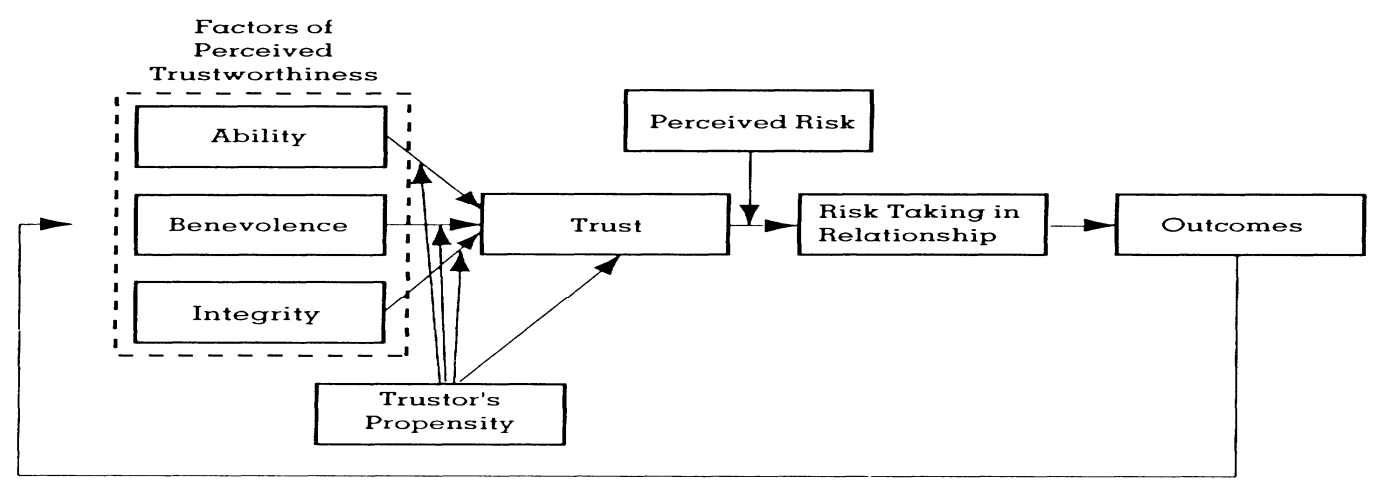




\subsection{Consumer Trust in E-commerce}

While trust matters in all forms of commerce, it is critical in e-commerce because consumers perceive higher degrees of risk and uncertainty on the internet [22]. Beldad et al. [23, pp.860] cite two risk factors, "the risk of losing one's money during the exchange" and "the threat of having one's private sphere penetrated". As consumers can only see the images or videos of products but cannot touch, feel or test them before purchase, uncertainty in product quality is another risk factor in e-commerce. Moreover, many statistics point to an increasing trend of online fraud. According to the 2013 Internet Crime Report [24], 262,813 online fraud complaints were filed in the U.S., with an adjusted dollar loss of approximately US\$ 780 million (48.8\% above the 2012 level). Hence, for many consumers, shopping online means exposing personal and financial information on the Internet, leading to concerns over privacy [25]. Another issue that plagues the online markets is security threats, such as dubious websites, fraudulent access or attacks on consumers' computers from hackers [26]. All these factors may erode the confidence in e-commerce.

Besides concerns of privacy and security, online shoppers also worry about unfamiliar online retailers. Daignault et al. [27, pp.2] assert that "Trust depends on identity, the condition of being distinguishable from others." Verification of the brick and mortar merchants' identity is relatively easier because factors such as premier location, investment in the store assortment, and personal communication with customers, signal quality in traditional settings. However, the very nature of the internet makes these features difficult to replicate in an online setting [28] and the absence of interaction with a live salesperson reduces the number of objects that online shoppers could build trust on [23]. Moreover, most online retailers are small in size and often lack the resources to invest in branding and advertising. Consequently, many shoppers feel nervous about issues such as order delivery, security of personal data and product quality - especially when they are first time visitors to a retail website. This lack of trust often motivates them to seek deeper discounts with these small retailers or to abandon their shopping carts and go to wellknown retailers. While there may also be other reasons behind shopping cart abandonment (e.g., compare 
prices, use the cart as a shopping list), "one of the major reasons why most online buyers abandon their shopping carts is because they feel the website is not trustworthy" [29]. As cart abandonment rate is increasing [30], online retailers are likely to benefit greatly by addressing consumers' trust concerns.

\subsection{Signaling trustworthiness in e-commerce and trust seals}

Observing that trust is a significant antecedent to consumers' purchasing decisions and loyalty [31], online retailers may signal their reliability and quality to potential customers in two major ways. The most straightforward way to do this is through a high-quality retail web site. Previous research shows that designing a professional and easy-to-navigate web interface [32], having a privacy policy [33], displaying contact information and past performance reports [34], superb technological capabilities of the retail web site [35], and quality of online service [36], all lead to customer satisfaction. As all of this information is provided by the online retailers themselves (also called first party information), consumers may find them biased which limits their effectiveness in persuading nervous shoppers.

Another commonly used way to signal quality and reliability is displaying trust seals of third parties. In fact, long before the first online purchase in 1979, trust seals were first offered in 1912 by the Better Business Bureau (BBB) which currently serves over 400,000 businesses in North America. In ecommerce, trust seals can be classified into three categories [12]: security seals, privacy seals and business identity seals. Security seals certify that the data transmission between the website and shopper is secured through SSL technologies and that the website is scanned regularly against malware (e.g., VeriSign, McAffee, GoDaddy). Privacy seals ensure that the online retailer has a privacy policy and treats the personal data of customers confidentially (e.g., TRUSTe, VeraSafe). Business identity seals are used to demonstrate that the online retailer's identity is true and that it is a real, trustworthy business (e.g," $\mathrm{BBB}$, buySAFE). While the trust seal could be displayed at a variety of locations, a common practice is to position a seal persistently at the right bottom corner of the retail website. Therefore, we can say that in the absence of institutionalized regulation on the internet, third party trust seals provide a creative solution to address the information asymmetry problem of the online retail industry. 


\subsection{Functioning of trust seals}

We adopt the integrative model of trust [21] as a theoretical lens in understanding the mechanisms behind the functioning of trust seals in different contexts. In the e-commerce setting, the trustor is the shopper who is vulnerable to the actions of the trustee - the online retailer and both parties are engaged in an exchange relationship. Accordingly, trust in the online retailer is mainly driven by three factors of perceived trustworthiness: ability, integrity and benevolence. Shoppers' perception of online retailer's ability (capacity, competence) and integrity to fulfill promises influence the trust in the online retailer. The trust level of the shopper, in turn, leads to risk taking in relationship (RTR), which is an online purchase in this context. This trust-RTR link is moderated by shoppers' perceived contextual risks. Following the above model, trust seals could enhance shopper's trust in two ways: First, by displaying the seal, the online retailers associate themselves with the seal provider which usually has a higher level of reputation in the industry. This association with a better known party is likely to enhance the perceived trustworthiness of the lesser known online retailer [8], which in turn increases shopper's trust in the retailer and likelihood of purchase from the retailer's website. Second, the trust seal could reduce the risks perceived by the shopper, such as delivery, quality and personal data. The trusted third party's endorsement could serve as an institutional trust building mechanism facilitating the "shopper trust purchase completion" link.

There have been many research studies conducted in the area of trust seals which made important contributions to the understanding of how trust seals function. While earlier papers provided mixed results on the role of trust seals, recently there seems to be some consensus that trust seals help increase conversion rates. Among early studies, Hu et al. [15] and Kimery and McCord [16] used simulated retail web sites and found that some seals are effective. Head and Hassanein [17] and McKnight et al. [14] used similar controlled settings but observed no significant effect of the trust seal. On the contrary, recent studies show evidence of strong support to the effectiveness of trust seals which could indicate the consumer acceptance of this mechanism. Using a scenario survey of 463 respondents, Chang et al. [11] 
found that third party certification is a successful trust-building mechanism in e-commerce. Similarly, Hu et al. [12] also used lab-controlled experiments and provide evidence that trust seals enhance customers' initial online trust.

Next, we develop four hypotheses about contextual factors that moderate the effectiveness of trust seals; namely, cart value, retailer's sales volume, shopper experience and number of other trust seals displayed at the retail website.

\section{Hypotheses development}

Differing product values are likely to justify various levels of consumer search costs. It is reasonable for a rational consumer to drive to a few stores before buying expensive furniture, but not for a bottle of water if it is available at the convenience store round the corner. As is well known, shoppers are more likely to be risk-averse when it comes to higher value purchases. In an e-commerce context, Nicholls [30, pp.26] suggests "higher value shopping carts are more likely to be abandoned due to longer cycles as customers took more time to research expensive purchases." Swan and Nolan [38] posit that trust is essential to complete transactions that contain a high degree of risk and information asymmetry. Trust is based on information and risky purchases that involve higher prices require more information to be completed [37]. Similarly, shoppers making high value purchases might want to collect more reliable information about the retailer before extending trust and completing the purchase. According to the integrative model of trust [21], the trust level is compared to the level of risk in the transaction. If the trust level is higher, then risk is taken. As high value purchases are more risky, we suggest that the trust seal could work better for completing high-value shopping carts by providing more information and reducing the risks perceived by shoppers. While we don't expect shoppers' trust in the online retailer to change with the value of purchase, endorsement by a trusted third party could help reduce the risks perceived by the shopper, thus facilitating the purchase completion. Hence we posit as follows:

\section{H1. The trust seal is more effective towards completion of higher value shopping carts than} lower value shopping carts in online retail industry. 
Most consumers feel more comfortable shopping at well-known online retail websites [39], which puts small online retailers at a disadvantage. Big players in the e-commerce world, such as "Amazon.com", have established reputation over years of business through millions of satisfied consumers where they also have significant vested interests (e.g., brand, capacity investments) that is larger than any incentive to cheat [40]. A merchant's reputation and brand serve as proxies for the merchant's credibility [41]. In a buyer-supplier context, supplier size has been shown to have a positive impact on the buyer firm's trust in the supplier [9]. In e-commerce, the perceived size of the online retailer has also been found to influence the shopper trust in the retailer [43]. Similarly, in increasing shopper trust in the retailer, third party certification is suggested to be more effective in unknown retailers' websites compared to well-known retail websites [11]. Hence, we test the following hypothesis:

H2. Online retailers with smaller sales volume benefit more from the presence of the trust seal than larger online retailers.

Previous shopping experience with a merchant is likely to play an important role on purchasing behavior as one would expect a satisfied customer to return for repeat purchases. "Power Law of Practice" theory has been used to explain the cognitive lock-in that customers experience at websites that they have previously visited, suggesting that these repeat customers are more likely to purchase [43]. Quantifying this likelihood, Nicholls [30, pp.15] notes "less than $1 \%$ of visitors will buy on their first visit" and "returning visitors that have made a recent purchase are three times more likely to purchase."

Trust develops over time as a result of repeated transactions [44]. According to the integrative model of trust [21], the outcome of the trusting behavior (here the completed purchase) is fed back to the factors of perceived trustworthiness, which means the shopper updates his/her perception of the online retailer's trustworthiness based on the satisfaction gained from the purchase history. While early in the relationship, integrity and ability of the trustor as perceived by the trustee matter most, perceived benevolence becomes more salient over time after some interactions. Hence after repeat purchases by a shopper, the online retailer's perceived trustworthiness is not only constructed by its ability and integrity but also by its benevolence. Gefen et al. [45] suggest that trust has a longitudinal dimension and the importance of 
reputation trust diminishes over time. As business partners become familiar with each other over time, both parties start to focus on the value of the transaction rather than initial reputation. Fazio and Zanna [46], who developed the theory of attitude-behavior consistency, posit that for repeat customers, satisfaction with a merchant is a more important determinant of trust building than reputation and structural assurance. While trust is a significant driver of purchase intention for all customers [47], customer satisfaction is the strongest antecedent amongst all trust building factors for repeat customers [48]. Consequently, we see that having previously purchased from an online retailer at least once, repeat shopper probably needs fewer assurances about that retailer for his/her next purchase. The narrowed trust gap between the online retailer and shoppers, after repeated transactions, is likely to reduce the need for a trusted third party's involvement in the form of a trust seal. Thus we expect that:

H3. The effect of the trust seal diminishes for more frequent shoppers at an online retail website.

Online retailers sometimes display multiple trust seals because "no current seal is capable of addressing all consumer concerns simultaneously" [49, pp. 82]. Information (trust cues) received from different sources strengthen each other, if they deliver consistent signals [50]. Similarly, multiple trust seals displayed at an online retailer's website, each addressing a different functional concern of online

shoppers (e.g., privacy, security, business identity), are likely to create some synergy. However, having multiple functions in a single trust seal is not necessarily better [12]. In this study, while we expect trust seals to be valuable and have a positive impact on purchase completion, we also anticipate the law of diminishing returns to apply to the context of trust seals. In other words, we expect the marginal impact of each additional trust seal on the purchase completion rate to be lower. Hence we hypothesize as follows:

\section{H4. As the number of trust seals at an online retail website increases, the marginal impact of} an additional trust seal on the completion likelihood of shopping carts diminishes.

The hypotheses discussed above are illustrated in Figure 2. 
Figure 2: Theoretical frame work

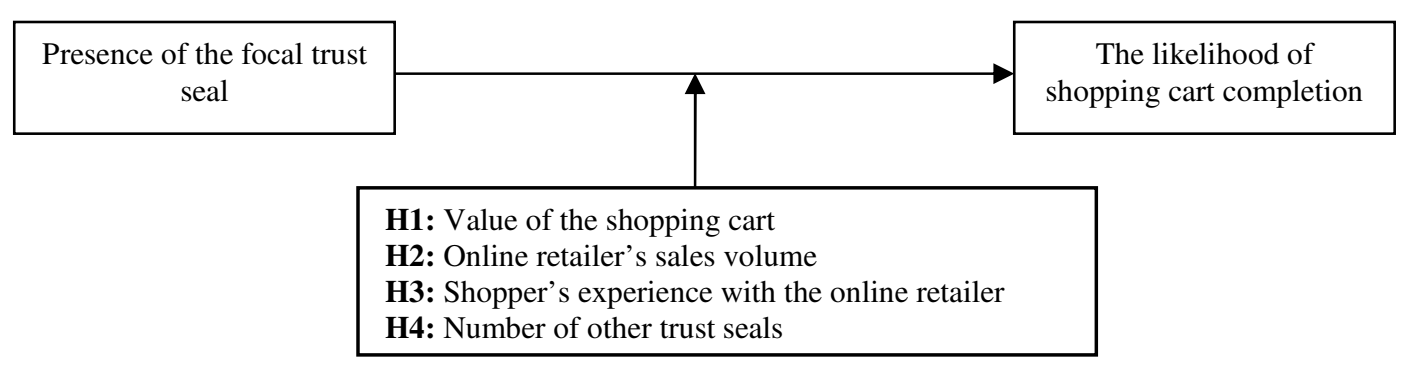

\section{Methodology and Data}

\subsection{Experimental Methodology}

We obtained our dataset from a major trust seal provider in the U.S. that runs experiments on its new customers' (online retailers) websites to identify the effectiveness of its trust seal on purchase completion. In this subsection, we provide some specifics of how the experiment has been conducted based on our conversation with the seal provider.

To measure the impact of its trust seal on key site metrics, the seal provider conducts a randomized field experiment called "A/B split tests" at the participating online retail websites upon retailer certification by the seal provider. In this single factor- two levels (1x2) experimental design, the participating retailers allow the seal provider to display the seal with $50 \%$ of the visitors to their web sites - so called A's, while not displaying the seal with the other 50\% - called B's. The assignment to be in set A or set B was random which ensures that there are no systematic differences between the two sets of shoppers other than the presence of the trust seal. Thus, the "A/B split test" allows us to establish causality and identify the seal's interaction with other variables.

The process of certification starts with online retailers' application to the seal provider. Our focal trust seal provider performs a stringent review of online retailers seeking a "trust seal" for financial stability, verifiable identity, and a successful business track record. Online retailers, satisfying the criteria determined by the trust seal provider, are then certified in return for a fee to be paid by the retailer. Our focal seal provider also requires that certified online retailers allow monitoring of website operations and 
performance in every transaction following certification and places a piece of JavaScript code at their websites. The code serves two purposes: to display the trust seal and to transfer the encrypted transaction details at the certified retail websites into the seal provider's own database, out of which our dataset was extracted. The focal trust seal logo is then displayed by the online retailer as an endorsement of its quality claims by an independent verification authority. The seal is persistently positioned at the right bottom corner of the retail website such that it is prominent enough to be noticed by the shoppers across all retailers. Shoppers can then verify the seal by clicking to check the certification status.

\subsection{Data}

The cross-sectional dataset used in this study includes actual shopping cart data collected from 493 online retail websites. It originates from a randomized field experiment ( $\mathrm{A} / \mathrm{B}$ split test) conducted by the seal provider at the online retail websites during the January 1 - October 15, 2007 period. Upon certifying retailers, the seal provider gives them the option to run "A/B split test" on their websites by turning the seal on and off randomly (based on the IP address of the visitor) in order to observe the seal's true impact on shopping behavior. The experiment on the retailer's website runs for a minimum of seven days up to multiple weeks until $95 \%$ confidence interval is reached. The level of observation is the shopping cart and each observation contains a set of data about the shopping cart, such as the status of the cart (abandoned or completed), the value of the cart (in U.S. dollars), retailer ID, email provided (if any), seal status (ON or OFF), cart start date, cart end date and product category. During the experiments, some variables remained constant, such as design of retail web sites and presence of other trust seals. The seal provider's director of analytics, who runs the experiments, also remained to be the same person.

Reviewing demographics of the 493 online retailers, we observe that they come from 41 different U.S. states with $19.55 \%$ based in California, $7.73 \%$ in Florida, $7.27 \%$ in Texas, $7.27 \%$ in New York and $4.55 \%$ in New Jersey. A variety of products from 25 different categories were carried by the retailers including Sporting Goods (22.31\%), Furniture (14.92\%), Movies (14.73\%), Books (6.97\%), Toys (5.08 \%), Clothing (4.99\%), and Electronics (4.10\%). While generic e-commerce platforms were preferred by 
$27.46 \%$ of the retailers, $14.37 \%$ built their retail websites on the Miva Merchant platform, $12.25 \%$ on Zoovy, $12.11 \%$ on Yahoo and $10.14 \%$ on the OS Commerce platform. The domain name extensions of the retail websites were mostly (92.96\%) “.com” followed by “.net” (4.23\%), “.org”( 0.99\%) and “.biz” $(0.70 \%)$. The Google page ranks of our retailers range from 0 to 8 , with a mean of 2.23; while the Alexa ranks range from 1 to 9.5 million, showing that there are many frequently visited and well networked retail web sites, as well as those with fewer hits and connections. Overall, we observe that our dataset is quite diverse and includes a large variety of U.S. online retailers.

Table 1 provides an overview of the data. Out of the 288,169 actual shopping carts comprising the dataset, the seal was displayed to approximately half (49.45\%) of the shoppers, while it was turned off for the other half $(50.55 \%)$. The average cart value is $\$ 256$. While shopping carts from 25 product categories are included, Sporting goods, Furniture, Movies, Books, Toys, Clothing and Electronics are the most common-comprising over $73 \%$ of all shopping carts. We observe that descriptive statistics of measures, such as cart value, number of other seals, and categorical distributions are very similar in both Seal=ON and Seal=OFF cases, except the cart completion percentage. As shoppers are uniquely identified by their e-mail addresses, a subset of the dataset comprising 136,569 carts have been used (we call this experience dataset) to test the shopper experience hypothesis. Many shoppers quit without entering any identifier data and we inevitably had some natural omissions as well.

Table 1: Descriptive summary statistics of our dataset

\begin{tabular}{llll}
\hline \hline & Whole dataset & SEAL ON & SEAL OFF \\
\hline Number of carts & 288,169 & 142,497 & 145,672 \\
Percent of total & 100 & 49.45 & 50.55 \\
Number of all carts completed & 69,644 & 35,704 & 33,940 \\
Percent of all carts completed & $24.17 \%$ & $25.06 \%$ & $23.30 \%$ \\
Average cart value & $\$ 256$ & $\$ 257$ & $\$ 255$ \\
Average number of other seals & 0.44 & 0.43 & 0.45 \\
Percent of all carts in Books category & $7.5 \%$ & $7.5 \%$ & $7.5 \%$ \\
\hline \hline
\end{tabular}

In addition to the focal seal, the seal provider also kept track of the presence of other trust seals at the retail web sites. We observe that $69 \%$ of the online retailers displayed no other trust seals, $22 \%$ displayed 
one other seal, $6 \%$ displayed two other seals, and 3\% displayed three or more other seals. Excluding the seal provider's own seal, an average of 0.45 other trust seals were displayed by the online retailers, ranging between 0 and 4 . A total of 14 other trust seals have been considered in our analysis which includes the following: Better Business Bureau (BBB), BizRate, GeoTrust, Google-Checkout, NexTag, PayPal, VeriSign, TRUSTe, PriceRunner, Comodo, ControlScan, RapidSSL, ScanAlert and Thawte. We should note here that during the field experiment, there was no variation in the number of other trust seals displayed by the retailers. For example, if a retail website displayed one other trust seal, it remained visible at a particular location constantly to all shoppers because only the focal seal was experimental (turned on and off) and the other seals did not go through an "A/B split test". Next, we introduce the measures used in our empirical model.

\subsection{Measures}

Our dependent variable "Completed" is binary and takes the value of " 1 " if the cart is completed, " 0 " otherwise. Completion rate is defined as the percentage of the checked-out (paid and purchased) carts among all created carts. The average completion rate of all carts in our dataset is $24.17 \%$. The independent variable "Seal_ON" is binary and takes the value of "1" when the seal is displayed and " 0 " otherwise. The "Seal_ON" variable has a mean value of 0.4945 .

"Cart Value" is the final dollar value of the cart when the shopper checked out, or abandoned the cart. The cart value has a sample mean of $\$ 256$ and ranges from $\$ 0.10$ to $\$ 93,209$. "Retailer Sales Volume" is a measure of online retailer's sales volume. It was computed by summing up the dollar value of all completed carts for each online retailer in our dataset. Average retailer sales volume turned out to be $\$ 1.48$ million ranging from $\$ 12.45$ to $\$ 22.7$ million. Treating each of the seals displayed at retail websites equally, we have counted the number of other seals (excluding the focal one) in each retailer's web site and called this "Total Number of Other Seals". To test for the diminishing marginal returns of additional

seals, we have log-transformed this variable in one of our models and squared it in two other models to test for quadratic relationships. 
The variable "Shopper Experience" measures the number of purchases that a shopper has cumulatively made at a particular online retailer's website. It is a dynamic variable calculated in a forward rolling fashion such that at the time of a cart creation, the experience of a shopper is the count of all completed carts by that shopper until that moment at that online retailer. The shopper experience ranges from 0 to 343 completed carts with an average of 1.08 carts.

The descriptive statistics of the five different variables used in our models are provided in Table 2. We observe that the experience dataset, which consists of fewer observations, has some differences. Given the cart completion rate of $50.99 \%$ for the experience dataset, shoppers who provided their email addresses are more likely to have advanced in the shopping cycle and they are more likely to complete the purchase. Pairwise correlations are reported in Table 3.

Table 2: Descriptive statistics of the measures

\begin{tabular}{lrrrr}
\hline \hline Variable & Mean & SD & Min & Max \\
\hline Completed & 0.2417 & 0.4282 & 0 & 1 \\
Seal_ON & 0.4945 & 0.4992 & 0 & 1 \\
Retailer Sales Volume (US \$) & $1.48 \mathrm{M}$ & $1.73 \mathrm{M}$ & 12.45 & $22.7 \mathrm{M}$ \\
Cart value (US \$) & 256 & 1,169 & 0.10 & $93 \mathrm{~K}$ \\
Total Number of Other Seals & 0.45 & 0.82 & 0 & 4 \\
Completed* & 0.5099 & 0.4661 & 0 & 1 \\
Seal_ON * & 0.5212 & 0.4996 & 0 & 1 \\
Shopper Experience * & 1.08 & 10.46 & 0 & 343 \\
\hline \hline
\end{tabular}

*Statistics from the experience dataset

Table 3: The correlation matrix

\begin{tabular}{lllll}
\hline \hline & $(1)$ & $(2)$ & $(3)$ & $(4)$ \\
\hline Seal_ON (1) & 1 & & & \\
Cart Value (2) & 0.001 & 1 & & \\
Retailer Sales Volume (3) & -0.041 & 0.097 & 1 & \\
Total Number of Other Seals (4) & -0.016 & -0.062 & -0.376 & 1 \\
\hline \hline
\end{tabular}




\section{Empirical analyses and results}

\subsection{Model Specification}

Our main objective in this paper is to study factors that could moderate the impact of trust seals on shopping cart completion. Since our dependent variable "Completed" is binary, we apply the following logistic regression model [51].

$$
\begin{aligned}
& \text { LOG }\left(\mathrm{PI}_{\mathrm{I} 1} / \mathrm{PI} \mathrm{I}_{0}\right)=\beta_{0}+\beta_{1} \text { Seal_ON }+\beta_{2} \text { Cart Value }+\beta_{3} \text { Retailer Sales Volume }+\beta_{4} \text { Shopper } \\
& \text { Experience }+\beta_{5} \text { Total Number of Other Seals }+\beta_{6} \text { Seal_ON*Cart Value }+\beta_{7} \text { Seal_ON* Retailer } \\
& \text { Sales Volume }+\beta_{8} \text { Seal_ON*Shopper Experience }+\beta_{9} \text { Seal_ON*Total Number of Other Seals }+ \\
& \text { Categorical dummies }+\varepsilon_{\mathrm{I}}
\end{aligned}
$$

where $\mathrm{PI}_{I 1}$ is the probability that cart number $\mathrm{I}$ is completed and $\mathrm{PI}_{\mathrm{I}}$ is the probability that cart number I is not completed.

The "Seal_ON" variable shows the status of the trust seal (i.e., whether it is turned on or off for that shopper). We also include control variables "Cart Value", "Retailer Sales Volume", "Shopper Experience", and "Total Number of Other Trust Seals". Interaction terms between "Seal_ON" and other variables are added to the empirical model to investigate the possible moderating effects tested by the four hypotheses. Finally, we add category dummies to further control for potential heterogeneity across different product categories.

Because interaction terms are included, we normalized "Retailer Sales Volume", "Cart Value" and "Shopper Experience". Thus, a unit increase in the normalized "Retailer Sales Volume" variable refers to a one standard deviation increase in actual volume of carts completed at that retail website. The correlation matrix, provided in Table 3, show no indication of multi-collinearity among independent variables. We also tested for a possible "over-dispersion" of the model's variance by comparing the expected variance of the dependent variable "Completed" (0.49) with the observed variance (0.43). As there is no significant difference, we conclude that over-dispersion is not a serious issue for our model. 


\subsection{Findings}

We have run four different models - main effects, interactions, quadratic and experience. The results are reported in Table 4 below.

Table 4: The logistic regression results of the four models empirically tested

\begin{tabular}{|c|c|c|c|c|}
\hline & (1) & (2) & (3) & (4) \\
\hline & Main Effects & Interactions & Quadratic & Experience \\
\hline Seal_ON & $\begin{array}{l}0.132 * * * \\
(0.009)\end{array}$ & $\begin{array}{l}0.144 * * * \\
(0.010)\end{array}$ & $\begin{array}{l}0.181 * * * \\
(0.011)\end{array}$ & $\begin{array}{c}0.347 * * * \\
(0.020)\end{array}$ \\
\hline Cart Value & $\begin{array}{c}-0.426 * * * \\
(0.027)\end{array}$ & $\begin{array}{l}-0.436 * * * \\
(0.026)\end{array}$ & $\begin{array}{l}-0.436 * * * \\
(0.026)\end{array}$ & $\begin{array}{l}-0.189 * * * \\
\quad(0.018)\end{array}$ \\
\hline Seal_ON x Cart Value & & $\begin{array}{c}0.019 \\
(0.052)\end{array}$ & $\begin{array}{c}0.008 \\
(0.052)\end{array}$ & $\begin{array}{l}0.099 * * * \\
(0.027)\end{array}$ \\
\hline Retailer Sales Volume & $\begin{array}{l}0.184 * * * \\
(0.006)\end{array}$ & $\begin{array}{l}0.267 * * * \\
(0.007)\end{array}$ & $\begin{array}{l}0.290 * * * \\
(0.007)\end{array}$ & $\begin{array}{l}0.973 * * * \\
(0.015)\end{array}$ \\
\hline Seal_ON x Retailer Sales Volume & & $\begin{array}{l}-0.160 * * * \\
(0.010)\end{array}$ & $\begin{array}{l}-0.184 * * * \\
(0.010)\end{array}$ & $\begin{array}{c}-0.390 * * * \\
(0.015)\end{array}$ \\
\hline $\log$ (Total Number of Other Seals) & $\begin{array}{l}-0.017 \\
(0.014)\end{array}$ & $\begin{array}{l}-0.013 \\
(0.014)\end{array}$ & & \\
\hline Total Number of Other Seals & & & $\begin{array}{l}0.236 * * * \\
(0.021)\end{array}$ & $\begin{array}{l}1.146^{* * * *} \\
(0.027)\end{array}$ \\
\hline (Total Number of Other Seals) $^{2}$ & & & $\begin{array}{l}-0.066 * * * \\
(0.006)\end{array}$ & $\begin{array}{l}-0.158 * * * \\
(0.009)\end{array}$ \\
\hline $\begin{array}{c}\text { Seal_ON x Total Number of Other } \\
\text { Seals }\end{array}$ & & & $\begin{array}{l}-0.090 * * * \\
(0.013)\end{array}$ & $\begin{array}{l}-0.237 * * * \\
(0.023)\end{array}$ \\
\hline Shopper Experience & & & & $\begin{array}{c}1.680 * * * \\
(0.165)\end{array}$ \\
\hline Seal_ON x Shopper Experience & & & & $\begin{array}{c}-0.972 * * * \\
(0.205)\end{array}$ \\
\hline Constant & $\begin{array}{c}-1.364 * * * \\
(0.008)\end{array}$ & $\begin{array}{c}-1.380 * * * \\
(0.008)\end{array}$ & $\begin{array}{c}-1.413 * * * \\
(0.009)\end{array}$ & $\begin{array}{c}0.682 * * * \\
(0.020)\end{array}$ \\
\hline \multicolumn{5}{|l|}{ Categorical dummies } \\
\hline Log Likelihood & $-153,969$ & $-153,810$ & $-153,721$ & $-76,148$ \\
\hline AIC & 307,957 & 307,642 & 307,468 & 152,327 \\
\hline BIC & 308,052 & 307,758 & 307,605 & 152,474 \\
\hline Pseudo R2 & 0.0338 & 0.0348 & 0.0354 & 0.1083 \\
\hline Number of Observations & 288,169 & 288,169 & 288,169 & 136,569 \\
\hline
\end{tabular}

Robust standard errors in parenthesis, $* * * \mathrm{p}<0.001, * * \mathbf{p}<0.01,{ }^{*} \mathbf{p}<0.05$ 
In the main effects model, the relationships between the independent variables and cart completion are investigated. The interaction model includes the interaction terms of independent variables with the trust seal. Quadratic model tests for a possible quadratic relationship between the "Total Number of Other Seals" variable and cart completion. Finally, we investigate the interaction of the trust seal with "Shopper Experience" variable in the experience model. Huber-White standard errors are reported, which is robust to the heteroskedasticity in the data. The model fit statistics (log-likelihood, pseudo R-squared, AIC and BIC) are reported to interpret the results of multiple models in reference to each other.

Column 1 shows the results with only main effects where the coefficient of the variable "Seal_ON" equals 0.132 and it is highly significant. This positive coefficient indicates that presence of the trust seal at a retail web site increases the odds of cart completion at that web site hence supporting the findings of the previous trust seals papers discussed in Section 2. "Cart Value" variable has a significant coefficient of -0.426 pointing to a negative relationship between cart value and purchase completion. "Retailer Sales Volume" has a significant +0.184 coefficient indicating that carts created at larger retail websites are more likely to complete.

In column 2, we add the interaction terms "Seal_ON $x$ Cart Value" and "Seal_ON $x$ Retailer Sales Volume" to the main effects model of column 1. We see that the "Cart Value" variable has a negative significant coefficient of -0.436 , indicating that higher value carts have a lower likelihood of completion. Surprisingly, introduction of the seal does not increase the completion likelihood of higher value carts, as the interaction term "Seal_ON $x$ Cart Value" has a positive but insignificant coefficient of 0.019. We should, however, note that the coefficient of the interaction term "Seal_ON x Cart Value" comes out to be positive and significant (0.099) in the experience model of column 4 . The dataset used to test the experience model is comprised of a subset of shoppers who entered their email addresses. This significant positive interaction term could indicate that the seal is effective on completion of higher value carts only for shoppers at the final stages of the shopping cycle. Hence, we find partial support for Hypothesis 2. 
Then, we examine whether "Retailer Sales Volume" moderates the effect of the seal. We see that carts created at websites of larger retailers have a higher likelihood of completion as the coefficient of "Retailer Sales Volume" variable is positive 0.267 and significant in column 2. The coefficient of the interaction term "Seal_ON $x$ Retailer Sales Volume" is negative, -0.160 and significant, which shows the moderating effect of the seal between retailer size and cart completion likelihood, and that smaller online retailers benefit more from the presence of the seal. Moving left by 1 SD at the "Retailer Sales Volume" axis, i.e. from $\$ 3.21$ million (sample mean $+1 \mathrm{SD}$ ) down to $\$ 1.48$ million (sample mean), the odds of cart completion is reduced by $30.6 \%$ in the absence of the seal. However in the presence of the seal, the reduction in odds of cart completion is only $11.3 \%$. Thus, we have support for Hypothesis 3 , as we see that presence of the seal moderates the impact of retailer sales volume on cart completion.

Next, we examine the results for "Shopper Experience" (column 4) and find support for Hypothesis 4. The "Shopper Experience" variable has a positive significant sign (1.680) which means repeat shoppers are more likely to complete their carts compared to novice shoppers at a particular online retailer. The interaction term "Seal_ON $x$ Shopper Experience" has a negative significant coefficient (-0.972) but smaller in magnitude when compared to the "Shopper Experience" variable, meaning that the value of the seal is lower for more experienced shoppers, lending support to Hypothesis 4. Comparing two shoppers Alice: a shopper who has previously purchased 1.08 times (Mean value), and Bob: a repeat shopper who has purchased 6.31 times (Mean + 0.5 SD) at a particular retailer's web site - we find that, all else equal, Bob's odds of cart completion at that online retailer is $131.6 \%\left(\mathrm{e}^{1.680 * 0.5}\right)$ higher compared to Alice's in the absence of the seal. In the presence of the seal, Bob's odds of cart completion at the same retailer is only $42.5 \%\left(\mathrm{e}^{(1.680-0.972) * 0.5}\right)$ higher compared to Alice's. We see that trust seals and prior shopping experience at the retailer are partial substitutes as shoppers with more experience do seem to be less influenced by the trust seal.

Our last hypothesis is related to the effect of additional trust seals on purchase completion likelihood. As reported in column 1, the "log(Total Number of Other Seals)" variable is insignificant which provides 
no support to our hypothesis. However, the negative coefficient $(-0.017)$ led us to investigate alternative functional relationships between the number of seals and conversion. Given the positive coefficient of the “Seal_ON" variable (focal seal) and negative coefficient of the log(Total Number of Other Seals) variable (other seals), we tested a quadratic relationship as illustrated in column 3. The first degree term "Total Number of Other Seals" has a coefficient of 0.236, the second degree term (Total Number of Other Seals $)^{2}$ has a coefficient of -0.066 , and the interaction term "Seal_ON x Total Number of Other Seals" has a coefficient of -0.090 , all three being statistically significant. Taking the partial derivative of "Y=Completed" with respect to the variable "X= Total Number of Other Seals", and equating to zero, we find that the probability of cart completion is maximized at $\mathrm{X}=1.79$ other seals when the focal seal is OFF ("Seal_ON" = 0), and at X = 1.11 other seals when the focal seal is ON ("Seal_ON" = 1). Counting the focal seal with others, cart completion is maximized approximately when two trust seals are displayed (1.79 and 2.11). These findings provide evidence that there is an inverted U-shape relationship between the number of seals displayed at an online retail website and the purchase completion rate.

Finally, checking the model fit statistics (log-likelihood, pseudo R-squared, AIC and BIC), we see that having interaction terms in models 2, 3 and 4 (compared to model 1) increases the pseudo R-squared value and reduce the AIC and BIC numbers pointing to some explanatory power of the interaction effects.

\subsection{Robustness checks}

It is well known that the (statistical) significance of a predictor is a direct function of the sample size. That is, larger sample sizes typically result in more significant results (i.e., smaller p-values), regardless of the effect size. As a result, there is a growing concern that large sample sizes render statistical significance meaningless [52]. To address that concern, we perform the following robustness tests [53], (i) p-value/sample size plot, (ii) estimate the model on random subsets of the data, and (iii) present effect sizes. We plot the p-value/sample-size chart shown in Figure 3. At approximately 5,000 observations, pvalue falls below $1 \%$ and stays well under this value up to the full sample size of 288,169 . Then, we estimate our models on random subsets: $10 \%$ (28,817 observations), 20\% (57,634 observations) and 50\% (144,085 observations) of the dataset that includes a total of 288,169 shopping carts. We observe that 
directions of the model coefficients remain the same and there is very little change in the coefficient magnitudes. Finally, in Section 5.2, we reported not only the statistical test results, but also the effect sizes for the independent variables (e.g., 10.34\% increase in retailer revenue when trust seal is displayed). Altogether, these lead us to conclude that the effect of the seal is not an artifact of the sample size.

Figure 3: p-value / sample size plot for the "Seal_ON" variable

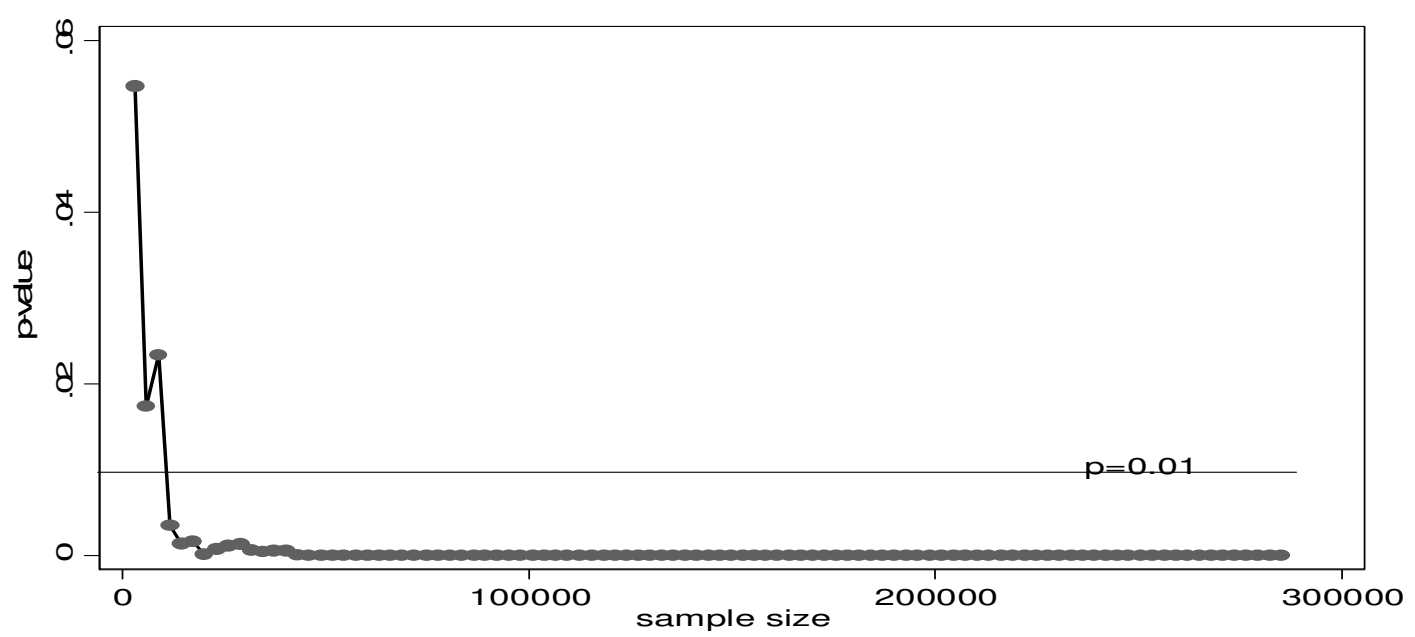

Logistic regression is known to underestimate the probability of rare events [54]. Since our dependent variable "Completed" is imbalanced (i.e., most carts are abandoned), we re-ran our logistic models with rare event correction procedures and observed that estimates are very similar to those generated in the ordinary logistic regression reported in Table 4. Finally, we change the functional relationship and estimate our models using probit regression. The results show that directions of the model coefficients remain the same and marginal effects are very similar.

\section{Discussion}

In this study, we extend the existing trusts seals literature by providing empirical evidence on how contextual factors influence the value of the trust seal. The seal is more effective on websites of small retailers and displaying too many trust seals to visitors could actually hurt purchase completion rates. Visitors with previous purchase experience at a retail website are influenced less by the seal rendering the seal more useful to new shoppers. Surprisingly, the shopping cart value had interaction with the seal only 
when shoppers advance to the latter stages of the shopping cycle. Finally, by using experimental field data, we provide empirical evidence that trust seals could actually increase cart completion rates. The size of our dataset comprising over a quarter million actual shopping carts created at 493 online retail websites coupled with the "A/B split test" methodology employed in data collection allows us to generalize our findings to the broader e-commerce world. Below, we provide a discussion of these findings and implications on online retailers and seal providers.

First of all, our work provides evidence that the trust seal partially substitutes for seller size/sales volume, indicating that small online retail stores benefit more from displaying the trust seal. Not surprisingly, large online retailers such as Amazon.com do not display any trust seals on their websites. The additional risk perceived by shoppers due to low business volume is partially mitigated by the presence of the trust seal. Our findings could be very helpful to seal providers who would profit by targeting small online retailers that actually benefit more from the presence of the trust seal. Consequently, trust seal providers can extract value by re-designing their pricing policies and provide discounts to attract larger retailers who are less likely to benefit from the presence of trust seals on their web sites. Some seal providers keep a directory of their approved online retailers on their web sites and allow shoppers to search for certified online stores. This search mechanism can direct visitor traffic to the more profitable online retailers based on the seal pricing policy, hence optimizing profits for the provider.

Our expectation that the seal would be more effective towards completion of high value shopping carts compared to low value shopping carts found partial support such that value of shopping cart moderates the effectiveness of the seal only for shoppers who have advanced through the shopping cycle (i.e., advanced enough to enter personal information). Using the comprehensive dataset that includes all shoppers, no moderating role of the cart value has been observed on trust seal's effectiveness. Apparently, many shoppers assess the risk of purchasing high-value carts when their monies and personal information are at stake, not while adding items to the cart. Therefore, the third party assurance information provided by the trust seal might be more functional in reducing perceived risks when the final risk assessment is 
made. While trust seal is effective across all shoppers, it could be even more valuable in persuading shoppers who are close to clicking the "Submit Order" button. Thus, online retailers could make the trust seal more salient to shoppers who have finished adding items to the cart and started entering personal information (e.g., display the trust seal next to credit card options).

Since online retail web sites sometimes display more than one trust seal, our findings also provide insights on the dynamic interactions among multiple seals. Referring to the results in section 5, cart completion rate is maximized when the focal seal is displayed with only one more other seal. Too many trust seals could actually reduce the cart completion rate. Further analysis indicates that there is an inverted " $U$ " shaped relationship between the total number of other displayed seals and purchase completion likelihood. This could be attributed to two reasons. First, shoppers may suffer from "feature fatigue", where addition of new features increases product complexity and consumer anxiety and stress $[55,56]$. Uneducated shoppers who are not aware of the function of the different trust seals may feel confused by the presence of many seals which would then lead to an abandoning of carts. Second, the presence of too many seals may make the shoppers skeptical about the online retailer's trustworthiness (i.e., why is this retailer trying so hard to prove its trustworthiness?). Our findings are consistent with that of $\mathrm{Hu}$ et al. [12] who find that more than two functions in combined-function trust seals could actually hurt shoppers' initial trust on the online retailer. It is prudent to note here that every seal is unique and might serve different purposes. Therefore, while our findings point to an optimal number around two trust seals, we believe the main take away from this finding is not the maximum point of the quadratic function but that more is not necessarily better with trust seals. We suggest that online retailers would do better by being selective about displaying only the few most effective seals.

Similar to conventional environments, a shopper's trust in an online retailer is likely to increase after a few successful online transactions. Thus, experienced shoppers are less likely to pay attention to quality signals but focus on their satisfaction with the online retailer in previous transactions. However, shoppers who have not yet interacted sufficiently with a particular retailer - new shoppers - have more difficulty in 
making a purchase decision. In reality, $74.6 \%$ of the new shoppers will not return back to the retail website after abandoning a shopping cart [30]. Therefore, persuading them to complete the very first purchase is of utmost importance for the retailers' long-term survival. Our research finds that trust seals work relatively better for these new shoppers who probably feel more comfortable when the online retail website displays the trust seal. The additional risk faced by a shopper due to lack of experience with a particular online retailer is mitigated significantly by the presence of a trust seal. Online retailers could use this finding in designing their operations by making the seal more visible and salient during sessions initiated by first time visitors. Customizing the information content delivered during the online purchase process decreases the information overload on customers [57] and displaying the trust seals selectively according to the customer needs is a smart "personalization" strategy. A typical online retailer's traffic consists of $10 \%$ repeat buyers that drive $25 \%$ of the sales and $90 \%$ first time visitors generating $75 \%$ of the sales [58]. These figures show that online retailers should pay attention to new shoppers and the trust seals could play a prominent role in this effort.

In conclusion, using actual shopping-cart and purchase data collected from field experiments conducted on certified online retailer web sites by a leading trust seal provider, this study identifies contextual factors which moderate the effectiveness of trust seals in cart completion. Our findings carry substantial value on (i) how online retailers could make better use of trust seals, and (ii) how seal providers could better market their products by targeting small retailers. Extending the body of existing trust seals literature by shedding some light on the seal's interaction with contextual factors, we hope that this work will lead to more nuanced analyses and better practice on trust seals.

\subsection{Alternative explanations}

In this subsection, we will discuss alternative explanations that could come up in interpreting our findings. First of all, it is important to note that our dataset probably includes some shoppers who might have been exposed to the trust seal at another website or through another device at the same retail website prior to the experiments. One would expect the manipulation (seal turned on and off) not to affect these 
shoppers as much. Unfortunately, our dataset does not allow us to identify those subjects. It is true that shoppers previously exposed to the seal might be less sensitive to the presence/absence of the trust seal. Fortunately, including these subjects should not harm our basic findings because including subjects who are immune to the experimental manipulation mostly just waters down the experiment. In other words if only a subset of the subjects are truly manipulated, then any significant results from the experiment would be conservative. Hence, having shoppers in the dataset who might have seen the trust seal at another website actually biases our results in a favorable direction. We argue that the magnitude of the trust seal's impact would be even stronger with shoppers all of whom are not immune to the experimental treatment.

Similarly, it is possible that some shoppers in the experimental group (seal on) do not pay attention to or see the displayed trust seal. In a field experiment, an online retailer would not ask the customers whether they have seen the trust seal. Therefore, presence of some subjects in the experimental group who were not truly manipulated might bias the results. Similar to the above case, we argue that this bias is in a favorable direction and it makes our results more conservative.

Another alternative explanation that we need to rule out is that the total number of seals displayed at a retail website may reflect an unmodeled merchant characteristic that is also correlated with the retailer's purchase completion rate (i.e., self-selection of adopting the seal). Put simply, desperate online retailers with low conversion rates may display more seals to attract customers which would make these variables endogenous [37]. To address this concern, we investigated the relationship between number of seals displayed at an online retail website and three retailer characteristics: (i) Alexa ranking of the retail website (ii) Google page rank of the retail website, and (iii) Sales volume of the online retailer. The correlations are: $-0.08,0.10$ and 0.04 respectively indicating that there is no strong association between an online retailer's hits on the internet and the number of seals displayed, nor is there a meaningful relationship between retailer sales volume and number of seals displayed. Hence, we can eliminate this alternative explanation as well. 


\section{Limitations and future research}

At a typical online store, many visitors just browse and leave without creating any cart. Our dataset is comprised of shopping carts and we can only measure the impact of the seal among shoppers who created a cart. The data does not allow us to examine the impact of trust seals on the creation of these shopping carts. However, as completion rate is a subset of conversion rate and assuming all else fixed, an increase in completion rate naturally leads to some increase in conversion rate. Second, McKnight et al. [14] found no significant difference in trust factors (e.g., structural assurance, dispositional trust) between early introductory stages of an online B2C relationship and the following exploratory stages later. This leads to additional support to the generalizability of our findings. Still, whether the online visitors who quit the store at the introductory stage perceive the trust seals as useful as shoppers who have actually created a cart is a valid question. Follow-up studies could use actual click-stream data to validate our findings.

Another limitation is the age of our data. The advance of mobile computing and widespread use of internet might have influenced the already complex trust formation process in e-commerce. It is important to replicate this study with a dataset that includes more shopping carts created by users of mobile devices. In addition, it is also important to keep in mind that the experiment was set-up by the trust seal provider himself who has a strong interest in the outcome of the results. While this does not necessarily imply any problems with the resulting data, our results should be interpreted and applied with that caveat in mind.

Our data lacks detailed consumer, product and website characteristics measures. While the A/B split test methodology employed in this study allows us to isolate the impact of trust seal on purchase completion of carts, it is important to note that outcomes of online shopping are influenced by multiple factors - presence of trust seals at the online retail website being just one factor amongst many. As the major goal of this paper is to examine the contextual factors facilitating the functioning of trust seals, future studies with more customer-specific measures can advance the understanding of the mechanism for trust seals to work at individual customer level. 
Our results are valid for U.S. merchants and shoppers in general but require caution before generalizing to other societies. Trust is a variable that distinguishes one society from another [59] and culture is a moderator of trust [45]. Thus, external validity of our results can be enhanced by testing our research questions with non-U.S. data.

\section{References}

[1] U.S. Census Bureau, Quarterly Retail E-commerce Report. Available at: http://www.census.gov/retail/mrts/www/data/pdf/ec_current.pdf Accessed on 10/16/2014.

[2] S.H. Kim, F. Byramjee, Effects of Risks on Online Consumers' Purchasing Behavior: Are They Risk-Averse Or Risk Taking? The Journal of Applied Business Research 30(1) (2014)161-172.

[3] L. Kuo, http://qz.com/147127/how-the-alibaba-of-india-is-teaching-india-to-trust-online-shopping/ (2013), Accessed on 7/1/2014.

[4] Mena, E-commerce features that will build trust, http://www.mena-360.com/\#!E-commerce-FeaturesThat-Will-Build-Trust/c1mmb/4EC0948E-2CD3-4F30-A849-C81EC49963DF (May 8, 2014).

[5] TRUSTe 2014 U.S. Consumer Confidence Index. http://www.truste.com/us-consumer-confidence$\underline{\text { index-2014/ }}$

[6] S. Wang, S.E. Beatty, W. Foxx, Signaling the Trustworthiness of Small Online Retailers, Journal of Interactive Marketing 18(1) (2005) pp. 53-69.

[7] Y D. Wang, H. H. Emurian,. An overview of online trust: Concepts, elements, and Implications, Computers in Human Behavior 21(1) (2005) 105-125.

[8] K. J. Stewart, Trust Transfer on the World Wide Web, Organization Science 14(1) (2003) 5-17.

[9] P. M. Doney, J. P.Cannon, M. R. Mullen, Understanding the influence of national culture on the development of trust, Academy of Management Review 23(3) (1998) 601-620. 
[10] K. Özpolat, G. Gao, W. Jank, S. Vishwanathan, The Value of Third-Party Assurance Seals in Online Retailing: An Empirical Investigation, Information Systems Research 24(4) (2013) 1100-1111.

[11] M .K. Chang, W. Cheung, M. Tang, Building trust online: Interactions among trust building mechanisms, Information and Management 50 (2013) 439-445.

[12] X. Hu, G. Wu, Y. Wu, H. Zhang, The effects of Web assurance seals on consumers' initial trust in an online vendor: A functional perspective, Decision Support Systems 48 (2010) 407-418.

[13] A. Nikitkov, Information Assurance Seals: How They Impact Consumer Purchasing Behavior, Journal of Information Systems 20(1) (2006) 1-17.

[14] D. H. McKnight, C. J. Kacmar, V. Choudhury, Shifting Factors and the Ineffectiveness of Third Party Assurance Seals: A Two-Stage Model of Initial Trust in a Web Business. Electronic Markets 14(3) (2004) 252-266.

[15] X. Hu, L. Zhangxi, H. Zhang, Trust Promoting Seals in Electronic Markets: An Exploratory Study of Their Effectiveness for Online Sales Promotion. Journal of Promotion Management (2003) 9(1/2).

[16] K. M. Kimery, M. McCord, Third Party Assurances: Mapping the Road to Trust in E Retailing, Journal of Information Technology Theory and Application 4(2) (2002) 63-82.

[17] M. M. Head, K. Hassanein, Trust in E-Commerce, Quarterly J. of Electr. Commerce 3(3) (2002) 307.

[18] Kyle Rush, (http://kylerush.net/blog/optimization-at-the-obama-campaign-ab-testing/), Accessed on $7 / 1 / 2014$

[19] A. Lo, Legacy of distrust through the ages, accessed on 7/4/2014, available at http://www.scmp.com/comment/article/1071995/legacy-distrust-through-ages

[20] F. Hirsch, Social limits to growth, Cambridge, MA: Harvard University Press, 1978.

[21] R. C. Mayer, J. H Davis, F. D. Schoorman, An Integrative Model of Organizational Trust, The Academy of Management Review 20(3) (1995)709-734. 
[22] J. Huh and W. Shin, Trust in Prescription Drug Brand Websites: Website Trust Cues, Attitude Toward the Website, and Behavioral Intentions, Journal of Health Communication (2014) 0:1-22.

[23] A. Beldad, M. de Jong, M. Steerhouder, How shall I trust the faceless and the intangible? A literature review on the antecedents of online trust, Computers in Human Behavior 26 (2010) 857-869.

[24] 2013 Internet Crime Report, Available at http://www.ic3.gov/media/annualreport/2013_ic3report.pdf Accessed on $7 / 4 / 2014$,

[25] D. L. Hoffman, T.P. Novak, M. Peralta, Building Consumer Trust Online, Communications of the ACM 42(4) (1999) 80-85.

[26] G. Udo, Privacy and security concerns as major barriers for e-commerce: a survey study, Information Management and Computer Security 9/4 (2001) 165-174.

[27] M. Daignault, M. Shepherd, S. Marche, C. Watters, Enabling Trust Online, Proceedings of the $3^{\text {rd }}$ International Symposium on Electronic Commerce (ISEC'02) (2002) 3-13.

[28] S. Ba, Establishing Online Trust through a Community Responsibility System, Decision Support Systems 31 (2001) 323-336

[29] V. Mollomo, How to Decrease Shopping Cart Abandonment, accessed on 7/4/2013, available at http://www.i2iwebmedia.com/blog/how-to-decrease-shopping-cart-abandonment/

[30] C. Nicholls, The Science of Shopping Cart Abandonment, accessed on 7/4/2014, available at http://seewhy.com/wp-content/uploads/SeeWhy_eBook_The_Science_of_Shopping_Cart_ $\underline{\text { Abandonment.pdf }}$

[31] D. J. Kim, D. L. Ferrin, H. R. Rao, Trust and Satisfaction, Two Stepping Stones for Successful ECommerce Relationships: A Longitudinal Exploration. Information Systems Research, 20(2) (2009) 237-257.

[32] A. E. Schlosser, T. B. White, S. M. Lloyd, Converting Web Site Visitors into Buyers: How Web Site 
Investment Increases Consumer Trusting Beliefs and Online Purchase Intentions, Journal of Marketing 70 (2) (2005)133-148.

[33] J.Y. Tsai, S. Egelman, L. Cranor, A.Acquisti, The Effect of Online Privacy Information on Purchasing Behavior: An Experimental Study, Information Systems Research 22(2) (2011) 254-268.

[34] D. J. Kim, I. Benbasat, The Effects of Trust-Assuring Arguments on Consumer Trust in Internet Stores: Application of Toulmin's Model of Argumentation, Information Systems Research 17(3) (2006) 286-300

[35] S. Ba, W.C. Johansson, An Exploratory Study of the Impact of e-Service Process on Online Customer Satisfaction, Production \& Operations Management 17(1) (2008) 107-119.

[36] J. M. Field, G. R. Heim, K. K. Sinha, Managing Quality in the E-Service System: Development and Application of a Process Model, Production \& Operations Management 13(4) (2004) 291-306.

[37] E. Benjamin, Adverse selection in online "trust" certifications, Proceedings of the 11th International Conference on Electronic Commerce, Taipei, Taiwan: ACM (2009).

[38] J. E. Swan, J. J. Nolan, Gaining Customer Trust: A Conceptual Guide for the Salesperson. Journal of Personal Selling \& Sales Management 5(2) (1985) 39.

[39] Gemalto, http://www.gemalto.com/php/pr_view.php?id=321, accessed on 1/12/2013

[40] P. M. Ippolito, Bonding and Nonbonding Signals of Product Quality. The Journal of Business, 63(1) (1990) 41-60.

[41] M. D. Smith, E. Brynjolfsson, Consumer Decision-Making at an Internet Shopbot: Brand Still Matters, The Journal of Industrial Economics 49(4) (2001) 541-558.

[42] S. L. Jarvenpaa, N., Tractinsky, M. Vitale, Consumer Trust in an Internet Store, Information Technology and Management 1 (2000) 45-71.

[43] E.J. Johnson, S. Bellman, G.L. Lohse, Cognitive Lock-In and the Power Law of Practice. Journal of 
Marketing 67 (2003) 62-75.

[44] L. T. Hosmer, Trust: The Connecting Link between Organizational Theory and Philosophical Ethics, Academy of Management Review 20(2) (1995) 379-403.

[45] D. Gefen, I. Benbasat, P. A. Pavlou, A Research Agenda for Trust in Online Environments. Journal of Management Information Systems 24(4) (2008) 275-286.

[46] R. H. Fazio, M. P. Zanna, Direct experience \& attitude-behavior consistency, Academic Press(1981).

[47] E. Garbarino, M.S. Johnson, The different roles of satisfaction, trust, and commitment in customer Relationships, Journal of Marketing, (63) (1999) 70-87.

[48] K. Hee-Woong, X. Yunjie, K. Joon, A Comparison of Online Trust Building Factors between Potential Customers and Repeat Customers. J. of the Assoc. for Info. Systems, 5(10)(2004) 392-420.

[49] D.P. Cook, W. Luo, The Role of Third-Party Seals in Building Trust Online, E-Service Journal 2(3) (2003) 71-84.

[50] N. Anderson, Foundations of information integration theory. Academic Press, New York, 1981.

[51] A. Agresti, Categorical Data Analysis, second edition, New York: Wiley \& Sons, 2002.

[52] W. H. Greene, Econometric Analysis. Prentice Hall, 2007.

[53] M. Lin, H.C. Lucas, G. Shmueli, Too Big to Fail: large Samples and the p_Value Problem, Information Systems Research 24(4) (2013) 906-917.

[54] G. King, L. Zeng, Logistic regression in rare events data. Political analysis 9(2) (2001) 137-163.

[55] D G. Mick, S. Fournier, Paradoxes of Technology: Consumer Cognizance, Emotions, and Coping Strategies, Journal of Consumer Research 25 (1998) 123-143.

[56] D. V. Thompson, R. W. Hamilton, R. T. Rust, Feature Fatigue: When Product Capabilities Become Too Much of a Good Thing, Journal of Marketing Research 42(4) (2005) 431-442.

[57] G Häubl, V Trifts, Consumer decision making in online shopping environments: The effects of 
interactive decision aids, Marketing Science (19) 1 (2000) 4-21.

[58] buySAFE White Paper, The Consumer Confidence Problem, Accessed on 7/4/2014, available at http://blog.buysafe.com/files/buysafe-whitepaper_030910.pdf (2013).

[59] G. Hofstede, Culture's consequences: International Differences in Work-related Values. SAGE, Beverly Hills, CA, 1980. 